М. И. Кошелев, В. Е. Везломиев. Гражданское общество и гражданская ответственность в постсоветской России

Научная статья

УДК 328.185

DOI: 10.18101/1994-0866-2021-3-55-66

\title{
ГРАЖДАНСКОЕ ОБЩЕСТВО И ГРАЖДАНСКАЯ ОТВЕТСТВЕННОСТЬ В ПОСТСОВЕТСКОЙ РОССИИ
}

\section{(c) Кошелев Михаил Иванович}

доктор философских наук, профессор,

Академия права и управления Федеральной службы исполнения наказаний

Россия, 390000, г. Рязань, ул. Сенная, 1

koshelesh@yandex.ru

\section{(C) Везломцев Виктор Евгеньевич}

кандидат философских наук, доцент, Академия права и управления Федеральной службы исполнения наказаний Россия, 390000, г. Рязань, ул. Сенная, 1

ve.vezlomtsev@yandex.ru

Аннотация. Автор рассматривает содержание понятия «гражданское общество» в его взаимодействии со своим исходным понятием «гражданин». Этот анализ делает возможным рассмотрение понятий «гражданственность», «гражданская и государственная идентичность», «гражданская ответственность» применительно к преодолению барьеров на пути становления гражданского общества в постсоветской России. В статье рассматриваются концепции понимания «гражданство» и «гражданское общество».

Анализируется тенденция не рассматривать гражданское общество исключительно как институт демократии и обнаруживать его присутствие в автократических режимах. Рассматриваются гражданские добродетели, благодаря которым возможно создание и существование механизма социального взаимодействия, а также условия функционирования гражданского общества. Подчеркивается важность понимания гражданства «как участия», а не «как подданства» для существования гражданского общества, анализируется противоречивая природа отношений гражданского общества и государства.

Ключевые слова: государство, гражданское общество, правовое государство, демократия, гражданин, гражданская ответственность, гражданская идентичность, государственная идентичность, «антигражданское общество», коррупция.

\section{Для цитирования}

Кошелев М. И., Везломцев В. Е. Гражданское общество и гражданская ответственность в постсоветской России // Вестник Бурятского государственного университета. Философия. 2021. Вып. 3. С. 55-66.

Я ль буду в роковое время Позорить гражданина сан.

К. Рылеев

Слова из эпиграфа в начале позапрошлого века звучали вызывающе и посвоему революционно. Ведь понятие «гражданин» было введено декретом Вели- 
кой французской буржуазной революции с целью подтвердить уничтожение сословного неравенства и провозгласить юридическое равенство всех членов общества независимо от происхождения и социального статуса. Сегодня же слово «гражданин» и звучит, и выглядит весьма обыденно, как для недавних советских времен (здесь все дружно вспоминают: «гражданин, пройдемте!» и «гражданин начальник!»), так и в ряду более современных понятий - «гражданское общество», «гражданственность», «гражданская ответственность». Тем не менее внимание к проблематике гражданского общества после перемен, произошедших и происходящих в России в последние десятилетия, просто зашкаливает. Гражданское общество стало целью, тем общественным идеалом, к которому зовут наши политики и политологи. Отсутствием или недостаточным развитием гражданского общества объясняются многие проблемы, стоящие перед страной.

Прежде чем обсуждать степень развития гражданского общества в России, нельзя не отметить, что историческое развитие не предоставило ей для этого значительных шансов. Конечно, островки относительно демократического самоуправления можно обнаружить в истории российского государства, но в основном российская действительность на протяжении многих лет определялась деспотическим правлением. Самодержавие не видело других возможностей удерживать в повиновении огромную страну, тем более что даже жестокие порядки не могли предупредить периодически возникавшие «бессмысленные и беспощадные» бунты.

В Европе же идея гражданского общества имеет долгую историю. Многочисленные источники содержат весьма противоречивые сведения. Одни утверждают, что гражданское общество существовало всегда и со временем лишь меняет свои формы. Другие ведут отсчет гражданского общества с периода подготовки и осуществления буржуазных революций (XVI-XVIII вв.). В любом случае можно предполагать, что как минимум элементы гражданского общества существовали и в античном, и в феодальном обществе. Само понятие «гражданское общество» восходит своими корнями к идее полиса Аристотеля (koinoia politike - гражданское общество), societas civilis Цицерона и идеям естественного права [8, с. 9].

Другое дело, что сами термины «гражданское общество», «правовое государство» не очень удачны. С этим согласны многие специалисты. Действительно, гражданское общество не просто совокупность граждан, как это представлялось Аристотелю [1, с. 5], а правовое государство - не просто государство, в котором есть право. Содержание и оценки данных понятий менялись не раз и продолжают изменяться, что создает трудности для достижения консенсуса при их определении. Однако в современную номенклатуру понятия перетекли из политического багажа классической либеральной эпохи и остались в качестве наиболее употребительных именно они.

В соответствии с традициями политического либерализма гражданское общество традиционно противопоставлялось государству как абсолютно доброе начало - абсолютно злому. Время показало, что это не так. Государство отнюдь не всегда является воплощением зла, более того, государство необходимо как источник права для гражданского общества, оно закладывает его институты, создает условия, возможности для их функционирования, если речь идет, конечно, о 
М. И. Кочелев, В. Е. Везломиев. Гражданское общество и гражданская ответственность в постсоветской России

правовом государстве. Гражданское общество, в свою очередь, может быть отягчено криминалом и коррупцией, ориентировано на принципы частного выживания, на уход от налогов, взяточничество и воровство, социальное расслоение.

В то же время именно идея гражданского общества соответствует представлениям о самоорганизующемся демократическом обществе, о консолидации интересов и волеизъявления свободных, полноправных граждан и их объединений, обладающих гражданскими, политическими и социальными правами и готовых к совместному давлению на государство, на олигархические кланы; оно есть духовное объединение людей на основе общих ценностей и идеалов.

В России такого гражданского общества не было во времена ни тоталитарного, ни авторитарного социализма. На вопрос, состоялось ли такое гражданское общество у нас сегодня, нельзя ответить однозначно. С одной стороны, невозможно не видеть радикальных изменений, связанных с появлением свободы слова, свободы передвижения, свободных выборов и т. п. С другой - такого духовного объединения, о котором речь шла выше, в стране действительно еще нет. Как справедливо отмечает Б. Г. Капустин, событие гражданского общества происходит там и тогда, где и когда индивиды перестают быть частными лицами («буржуа») и становятся гражданами в собственном смысле слова [6, с. 58]. То есть до уровня, статуса гражданина частному лицу необходимо подняться. Во вступительной статье к этой работе В. С. Малахов цитирует американского социолога Р. Брубейкера, который утверждает, что гражданство является изобретением Французской революции [6, с. 66-67]. В свое время об этом же писал Ф. Энгельс, рассматривая вхождение относящихся к немецкому этносу жителей Эльзаса и Лотарингии, «в единый народ с исконными французами», как результат сотен сражений в борьбе за революцию против немцев, пытавшихся навязать французам старое феодальное рабство [14, с. 460-461].

Проблема гражданства к 1990-м годам стала объектом исследования мыслителями практически всех политических течений. Известный канадский исследователь Уилл Кимлика отмечает, что если раньше классические либералы верили, будто либеральная демократия может эффективно функционировать даже при отсутствии особо гражданственного населения, то сегодня выяснилось, что здоровье и стабильность современной демократии зависят не только от справедливости ее базовых институтов, но также от наличия у граждан чувства национальной, региональной, этнической или религиозной идентичности; от их желания участвовать в политическом процессе для того, чтобы способствовать общему благу и держать политические власти подотчетными; от их желания демонстрировать самоограничение и проявлять ответственность в экономических требованиях и в личном выборе, затрагивающем их здоровье и окружающую среду. Без граждан, обладающих этими качествами, демократии становятся трудноуправляемыми, даже нестабильными [7, с. 363].

Отсюда понятна неоднозначная связь между гражданином и гражданским обществом, гражданской и государственной идентичностью. Не случайно тот же Б. Г. Капустин сомневается в том, что правильное определение гражданства в принципе возможно, и, ссылаясь на обзор современной западной литературы по 
теории гражданства, указывает, что из шести ее разновидностей лишь одна указывает на связь «гражданства» и «гражданского общества» [6, с. 54-55].

В западной социологии существуют теории, понимающие «гражданство» как производное от государства, а «гражданское общество» - как производное от социальной сферы, отличной от государства. Такой подход позволяет сразу же отделить коллективы, которые не могут не быть частью гражданского общества, но целью которых выступает их частный интерес. Члены этих коллективов безусловно являются гражданами, но их интересы, их цели связаны с благополучием только этих перераспределительных групп. В то же время гражданское общество предполагает борьбу за гражданские, политические и социальные права всех членов общества. И это различное содержание понятий всегда должно учитываться. Таким образом, споры о том, существует или не существует сегодня в России гражданское общество, нередко зависят от того, в каком смысле употребляется это понятие. Так, А. Е. Аузан пишет, что гражданским обществом можно считать уже простейшие формы самоорганизации, договоренности о коллективных действиях [2, с. 76-77]. Соглашаясь с этим, социолог А. Левинсон полагает, что первые «гражданско-подобные» социальные образования в России 80-90-х гг. - мафиозные структуры [2, с. 78]. Здесь скорее может подойти понятие антигражданского общества. Но об этом - ниже.

Получается, что может возникнуть общество, в котором много самоорганизации, но преобладают многочисленные перераспределительные союзы, которые «тянут одеяло на себя». Действительно, в стране существуют социальные группы со своими специфическими интересами, члены которых должны консолидироваться для защиты своих групповых интересов в сферах политики, экономики, культуры перед лицом государства и других подобных групп. Можно ли назвать такое общество гражданским?

Но гражданин отличается от обывателя, тем более мафиози, прежде всего тем, что готов добровольно действовать и объединяться с другими гражданами, чтобы вместе отстаивать уже общие, межгрупповые интересы гражданского общества перед лицом власти. Понятно, что в разных ситуациях необходим и различный набор социальных качеств индивидов в зависимости от того, решают ли они задачи, отвечающие потребностям данной небольшой группки, или широких объединений, а то и всего общества. В первом случае задействован индивидуальный эгоистический интерес «экономического человека». Во втором - потребность в общем благе, готовность пожертвовать ради этого общего блага собственным благополучием, начиная от затрат личного времени, чтобы выйти на акцию протеста или к избирательной урне, и заканчивая риском лишиться свободы, а то и жизни, защищая этот общий интерес.

Здесь гражданское общество подстерегает серьезное препятствие. Глубочайший системный кризис, потрясший самые основы российского общества в 1990-е гг., расколол его на кучку миллиардеров и мультимиллионеров, с одной стороны, и обездоленное большинство населения - с другой. Если верить социологам, на долю $1 \%$ самых богатых приходится $71 \%$ всех личных активов в России. Во всем мире этот показатель равен $46 \%$, в Европе - $32 \%$. Российские миллиардеры владеют $30 \%$ всех личных активов россиян, а в среднем в мире 
М. И. Кочелев, В. Е. Везломиев. Гражданское общество и гражданская ответственность в постсоветской России

миллиардеры владеют лишь $2 \%$ всех личных активов [9, с. 7-8]. Отъем и раздел общенародной собственности кучкой олигархов, массовое ограбление народа на «законных» основаниях - все эти вопиющие нарушения общественной морали, элементарных норм социальной справедливости не могли не вызывать народное возмущение. Надежды на демократическое преобразование общественных отношений в интересах всего населения не оправдались. Большинство населения уверено в том, что приватизация в России осуществлялась преступным путем, с согласия и при активном участии тогдашнего политического руководства. Отсюда - низкое общественное доверие и к политической, и к экономической элите. Фактически ни один из институтов власти не вызывает у большинства респондентов доверия, за исключением президента.

Помимо катастрофического расслоения общества обращает на себя внимание фактор глубокой «атомизации» россиян. Он проявляется в низком уровне доверия друг к другу, разрушении горизонтальных связей, которые во многом объясняются особенностями рыночной экономики. Ссылаясь на исследования Института сравнительной политологии, А. А. Аузан отмечает, что по сравнению с западноевропейскими странами уровень межличностного персонифицированного доверия в России примерно в 3 , а то и в 3,5 раза ниже, чем у них [2, с. 214-215].

В такой ситуации говорить о консолидации общества вряд ли возможно. И как в таких условиях бороться за общий интерес, когда на самом деле эти интересы полностью противоположны. Да, бизнес с трудом выживает в душной атмосфере российской коррупции, но может ли он рассчитывать на поддержку гражданского общества в условиях такого расслоения? Население с радостью встречает известия об очередном аресте проворовавшегося бизнесмена, не интересуясь доказательствами обвинения. Простой человек не верит в возможность честно заработать миллиарды в наших условиях и, как видим, основания для такого неверия имеются. В этой ситуации бизнес и государство скорее договорятся друг с другом без участия гражданского общества, так как они зачастую вместе заинтересованы в коррупционных схемах. Точнее, гражданское общество потребуется, конечно, но исключительно для камуфлирования этого альянса. И действительно, в литературе отмечается, что авторитарные режимы целенаправленно используют авторитет и возможности институтов гражданского общества для мониторинга и управления социально-политическими процессами, а также включают в свои общественно-политические структуры гражданские ассоциации, чтобы нейтрализовать их действия, способные помешать политическому контролю над обществом. С другой стороны, и гражданские ассоциации заинтересованы в плотном контакте с государством, даже недемократическом, ибо оно в определенном смысле гарантирует «правила игры», включающие доступ к получению ресурсов. На этом основании прослеживается тенденция не рассматривать гражданское общество исключительно как институт демократии и обнаруживать его присутствие в автократических режимах [3].

В то же время гражданское общество пытается как-то контролировать тесный альянс государства и бизнеса, особенно в их крайних скандальных проявлениях, связанных с нарушениями законодательства, прав и свобод человека, социальной справедливости. Но как же «частный гражданин», озабоченный личными эконо- 
мическими интересами («экономический человек» никуда не делся), окажется готовым к бескомпромиссной борьбе за общегражданские ценности? Это возможно лишь в том случае, если интерес, объединяющий «экономических человеков», будет как минимум не меньшим, чем интерес личный. Что, в свою очередь, требует наличия у его сторонников, во-первых, осознания принадлежности к определенному сообществу граждан (от социальной группы до государства), а также определенных духовно-нравственных качеств, мужества, самоотверженности, взаимного доверия.

Индикатором такой совокупности качеств, которая обозначается понятием «гражданская идентичность», выступает доверие к окружению, к государственным и общественным институтам. Последнее тесно связано с государственной идентичностью, то есть с самоотождествлением себя со своим народом, государством. Именно страна, государство, язык культура, религия сближают и объединяют людей. Гражданское общество не может быть терпимым к космополитизму российской элиты, чьи интересы и жизненные стратегии во многом ориентированы на Запад. Неслучайно население с энтузиазмом встретило поправку в Конституцию, запрещающую высокопоставленным чиновникам иметь недвижимость и счета заграницей. Государство также вправе рассчитывать на ответственное поведение граждан в различных областях социальной жизни, начиная от заботы о собственном здоровье (отказ или существенное ограничение от алкоголя и курения), заботы о детях и престарелых (как минимум, алиментные обязательства), заботы об окружающей среде и др. Гражданские добродетели такого рода, создающие механизм социального взаимодействия, сегодня называют «социальным капиталом», и государству имеет прямой смысл инвестировать в него серьезные средства, ибо такие связи являются мощным ресурсом, способствующим росту благосостояния, снижению уровня бедности и социальной несправедливости, доверию и чувству личной ответственности за происходящее. В качестве примера гражданского поведения можно привести ситуацию, сложившуюся в связи с пандемией коронавируса, которая потребовала от граждан и самоконтроля, и ответственности. Сегодня уже можно судить о степени развитости гражданских качеств населения разных стран. Высокая дисциплина из привычного страха перед начальством оказалась в данном случае эффективнее демократического чувства ответственности за себя, коллектив, страну; чувства взаимного доверия между гражданином и государством.

Здесь необходимо согласиться с Г. Г. Дилигенским, который полагает, что необходимым условием функционирования гражданского общества является существование определенного типа личности, отличающейся не только высоким уровнем индивидуальной автономии по отношению к социуму вообще и к государственной власти в особенности, но и способностью конструктивно взаимодействовать с другими личностями во имя общих целей, интересов, ценностей, а также способностью подчинять свои частные интересы и способы их достижения общему благу, выраженному в правовых нормах [4].

Видимо, о таком типе личности Кондратий Рылеев писал в своем стихотворении, подчеркивая высокий сан (статус) гражданина. Быть гражданином - значит не только брать на себя определенные обязанности перед государством, но также 
М. И. Кочелев, В. Е. Везломиев. Гражданское общество и гражданская ответственность в постсоветской России

пользоваться правами и свободами, гарантированными имеющимся законодательством. Гражданин не просто имеет право, он обязан защищать свои права, если на них посягает кто-либо, и прежде всего - государство.

Такое понимание гражданства, «как участия», противостоит его пониманию «как подданства», которое пока, к сожалению, более характерно для нашей страны. Гражданство как участие предполагает возможным и законным как автономию личности, так и самоорганизацию граждан для отстаивания общих интересов и целей. Но необходимо отметить, конечно, сугубо формальный характер набора гражданских и политических прав. Гражданами, а не членами сословий и гильдий, в свое время сделал людей переход от традиционного общества к буржуазному и современному. Сегодня в качестве полноправных членов гражданского общества рассматриваются и с трудом сводящие концы с концами обыватели, и хозяева предприятий, директора банков и т. п. Естественно, реализовать свои социальные и политические права, прописанные в основополагающих документах, простому человеку намного труднее. Для этого должны существовать определенные условия. В действительности, будучи полноправными членами общества, отдельные категории граждан оказываются в безнадежной ситуации, не имея реальных шансов ни на приобретение возможных жизненных благ, ни на изменение своего положения в социальной структуре.

Приходится признать, что сложившаяся после падения Советского Союза ситуация поражает социальные связи намного интенсивнее по причине небезуспешных попыток разрушения духовных основ российской нации, извращения ее культурного кода, усвоенного и укорененного глубоко в коллективном сознании, традиционных представлениях о добре и зле. Православие, да и социалистическое воспитание пустили достаточно глубокие корни в души людей, и большинство не может признать нормальным и справедливым неправедно нажитое богатство. Культурный шок от реформ, в одночасье провозгласивших частный интерес выше общественного, интересы личности выше интересов коллектива, вдруг возникший культ денег - просто ошеломили (в прямом смысле слова) людей. Во все времена и у всех народов героями считались люди, жертвующие собой ради общества, «за други своя», но никак не жертвующие общественным интересом ради личной выгоды. А тут вдруг статусы «братка» и т. п. оказались выше статуса рабочего, ученого, офицера. В сознании простых людей это выглядело примерно так, как если бы сказочная Аленушка, бросив братца Иванушку, вышла замуж за Кощея, и стали они «жить-поживать и добра наживать». Такое не умещалось в голове, но жизнь демонстрировала факты очень похожие. Из-за денег дети заказывали убийства родителей, мужья - жен и наоборот. А как делят в судах наследство самые близкие люди!

Вопиющее материальное и социальное неравенство выдвинуло в России на первый план как наиболее острую и актуальную - проблему социальной справедливости. Властный запрос на воспроизводство признанных ценностей в основных сферах жизнедеятельности общества требует вмешательства такой общественной силы, с которой государство обязано считаться. Гражданское общество и представляет такую силу. 
Как уже отмечалось выше, государство и гражданское общество не просто тесно связаны друг с другом, правовое государство само создает необходимые условия для существования и развития гражданского общества. Однако без активного участия гражданского общества невозможно обеспечить согласие всех социальных групп относительно выработки общенациональной программы развития и общества, и государства. Фундаментальными ценностями, объединяющими социальные группы, выступают основные права и свободы человека и гражданина. И здесь проявляется противоречивая природа отношений гражданского общества и государства. Любая власть, и даже власть в правовом государстве, стремится, подчеркнем, из лучших побуждений (другие варианты здесь не рассматриваются), контролировать общественное мнение, а тем самым и социальную активность граждан. Не беря во внимание социальные и политические аспекты, просто с точки зрения чистой психологии стоящие у власти уверены в том, что если бы они не были умнее других, то вряд ли оказались бы на этом месте. А если при этом вся необходимая информация для принятия решений оказывается у них же, то любые попытки оспорить эти решения, тем более выступить против, в лучшем случае могут быть признаны недостаточно профессиональными, в худшем же - вредительскими. Похоже, что именно так рассуждают представители государственной бюрократии, пытаясь сохранить и даже усилить опеку государства над структурами гражданского общества.

При этом нельзя не видеть, что на интерес власти работает и известная пирамида Маслоу. До тех пор, пока не будут удовлетворены непосредственные материальные интересы населения, более высокие потребности, в том числе в гражданских правах, остаются за горизонтом его требований. Это понимали и советские, и восточноевропейские диссиденты, а также власть. Диссиденты акцентировали внимание на удовлетворении прав человека и гражданина, права на человеческое достоинство, утверждая, что достоинство необходимо человеку больше, чем калории [13, с. 76-77]. Власть же подчеркивала свою заботу об удовлетворении необходимых материальных потребностей — права на труд, пенсии, социальные гарантии. И даже при явных проблемах с их удовлетворением, выглядела (и продолжает выглядеть) гораздо убедительней. Видимо именно в этом одна из причин постоянных поражений представляющих либеральные ценности партий на российских выборах всех уровней.

Не забываем при этом, что целью правового государства является все-таки защита и дальнейшее развитие демократических порядков, вовлечение все большего количества граждан в политический процесс. Данная ситуация стимулирует попытки власти поддерживать постоянные контакты с обществом, порождать в центре и на местах общественные палаты, общенародные фронты, волонтерские движения.

Связь с общественными структурами, бесспорно, придает власти легитимности и позволяет в большей степени соответствовать существующим в обществе представлениям о справедливости. Можно согласиться с утверждением, что создание системы общественных палат является попыткой создания патерналистской модели взаимодействия власти и общества, при которой государство разрешает определенную автономию гражданских структур при условии, что они не 
М. И. Кочелев, В. Е. Везломиев. Гражданское общество и гражданская ответственность в постсоветской России

вмешиваются в дела власти. В обмен на политическую лояльность власть представляет определенные преференции в виде экономических, финансовых и других благ [12]. Однако структуры гражданского общества, которые насаждаются «сверху», от имени государства, теряют значительную долю автономии от него в глазах населения (о полной независимости речь и не может идти) и не оправдывают возлагаемых на них надежд. Отсюда - публичные протестные акции, периодически повторяющиеся в стране и выражающие гражданский запрос на необходимость перемен в социальной жизни. В то же время важно отметить следующее: даже несанкционированные митинги, забастовки должны подсказать властям, что помимо мер уголовной политики необходимо внимательно проанализировать, насколько правовые предписания соответствуют условиям их реализации. А то, что с этой точки зрения у нас не все в порядке, не вызывает сомнений. Иначе процент обвинительных приговоров в судах не превышал бы кратно процент таких приговоров в печально известном 1937 г. Представители исторической школы права учили, что юридические установления должны отвечать правовым обычаям народа, «духу народа». Законодатель должен облекать в правовую форму то, что «угадывается» в духе народа, а не пытаться конструировать право из своих представлений, тем более из желания угодить начальству.

Помимо названных выше барьеров на пути создания гражданского общества, следует особо отметить такую опасность, как организованная преступность. Большинству специалистов и не только специалистов ясно, что победить преступность усилиями лишь федеральных органов государственной власти невозможно. Требуется активное участие институтов гражданского общества, организаций и просто физических лиц.

Среди относительно новых форм организованной преступности в постсоветской России стоит упомянуть возникновение антигражданского общества.

Несмотря на некоторую экзотичность этого отрицательного определения, оно уже активно используется в научной литературе и публицистике, имеет свою историю, а значит присутствует в общественной жизни, и социальная теория настойчиво нащупывает его сущностные характеристики $[10 ; 11]$.

Совершенно справедливо российские социологи и экономисты отмечали, что организованная преступность взметнулась особенно высоко в 1990-е гг., когда государство оказалось ослабленным, фрагментированным в части основных государствообразующих функций. Конечно, сегодня не 1990-е годы, однако ситуация ненамного лучше. Исследуя силовое давление на бизнес, социологи, оценивая феномен рейдерства в современной России, считают возможным сравнивать его с айсбергом, отмечая, что для изучения доступна только небольшая видимая часть явления, то есть случаи, доходящие до суда, но и эта часть впечатляет [5].

В результате в масштабах страны возникла сложная структурированная система полулегальных и нелегальных организаций и групп, опирающихся на органы власти, система, по сути представляющая собой антигражданское общество. Существующими и постоянно вновь формирующимися элементами антигражданского общества являются коррумпированные чиновники, начиная с местных, региональных и заканчивая федеральными; коррумпированные представители 
силовых структур; коррумпированные суды, нотариусы. Очевидно, что формирование антигражданского общества находится в прямой связи с динамикой коррупции, которая за последние десятилетия достигла масштабов национальной катастрофы. Извлечение публичными лицами и прежде всего государственными чиновниками личных выгод из своего служебного, должностного положения приобрело гигантские масштабы, объем оборотных коррупционных средств достигает сотен миллиардов рублей. В такой ситуации не приходится думать, будто государство существует независимо от коррупции, будто коррупция приходит откуда-то извне и является чем-то вроде ржавчины на здоровом теле государства.

Особая опасность таких сообществ в том, что, имея скрытый, нелегальный характер, находясь все время в тени, они тесно связаны с официальными структурами и за счет этого остаются невидимыми и неуязвимыми для спецслужб, тем более в том случае, если их представители сами являются составной частью этих преступных группировок. Сетевая организация государственного силового предпринимательства - еще одно свидетельство самоорганизации антигражданского общества. Оно строится на принципах личных отношений между государственными служащими; в сетях задействованы не отделы и управления, а отдельные чиновники из различных ведомств. В результате сложных рекомбинаций официальных и неофициальных структур образуются новые сети.

Раковая опухоль антигражданского общества, пронизывающая всю систему отношений сверху донизу, имеющая к тому же тенденцию к росту, не позволяет смотреть в будущее с оптимизмом.

События будущего в современных условиях очень трудно предсказать (впрочем, когда это было легко?). На наших глазах пандемия короновируса меняет мир. Страхи перед смертельными болезнями, растущей угрозой новой мировой войны, безработицей, непросчитываемые последствия внедрения искусственного интеллекта и другие проблемы требуют исключительно высокого чувства ответственности от каждого человека. И формирование человека гражданского общества - гражданина, о котором писал Рылеев, сегодня актуально не только в теоретическом плане, ибо от социокультурных характеристик, достигнутых этим гражданином, зависит и устройство мира, в котором нам жить.

Лuтература

1. Аристотель. Политика. Москва; Ленинград: Наука, 1965. 393 с. Текст: непосредственный.

2. Аузан А. Е. Три публичные лекции о гражданском обществе. Москва: ОГИ, 2006. 283 с. Текст: непосредственный.

3. Бедерсон В. Д. Гражданские ассоциации и политический режим в мировой недемократической практике: между политическим контролем и социальной эффективностью // Полис. 2020. №2. С. 37-52. Текст: непосредственный.

4. Дилигенский Г. Г. Что мы знаем о демократии и гражданском обществе // Pro et Contra. 1997. Т. 2, № 4. С. 5-21. Текст: непосредственный.

5. Казун А. П. Не можешь победить - управляй: смены губернаторов, политическая конкуренция и рейдерство в регионах России // Общественные науки и современность. 2020. № 2. С. 108-120. 
М. И. Кочелев, В. Е. Везломиев. Гражданское общество и гражданская ответственность в постсоветской России

6. Капустин Б. Г. Гражданство и гражданское общество. Москва, 2011. 224 с. Текст: непосредственный.

7. Кимлика У. Современная политическая философия: введение. Москва, 2010. 588 с. Текст непосредственный.

8. Кучерена А. Г., Дмитриев Ю. А. Гражданское общество в России. Проблемы становления и развития: учебное пособие. Москва: ЮНИТИ: Закон и право, 2009. 255 с. Текст: непосредственный.

9. Макаров Т. Общество травмы: между эволюцией и революцией (круглый стол) // Социологические исследования. 2019. № 6. С. 3-14. Текст: непосредственный.

10. Мотрошилова Н. В. О современном понятии гражданского общества // Вопросы философии. 2009. № 6. С. 12-32. Текст: непосредственный.

11. Мотрошилова Н. В. Цивилизация и варварство в эпоху глобальных кризисов. Москва: ИФРАН, «Канон+» РООИ «Реабилитация», 2010. 480 с. Текст: непосредственный.

12. Сунгуров А. Ю., Козлова Н. Н., Мамагулашвили Д. И. Общественные палаты как институты реализации патерналистской модели взаимодействия власти и общества: опыт Тверской области и Санкт-Петербурга // Полис. Политические исследования. 2020. Т. 29, № 3. С. 93-109. Текст: непосредственный..

13. Шацкий Ш. Е. Протолиберализм: автономия личности и гражданское общество // Полис. Политические исследования. 1997. № 5. С. 68. Текст: непосредственный..

14. Маркс К., Энгельс Ф. Роль насилия в истории // Соч. 2-е изд. Москва, 1961. Т. 21. 782 с. Текст: непосредственный.

Статья поступила в редакцию 06.08.2021; одобрена после рецензирования 03.09.2021; принята к публикациии 14.09.2021.

\section{CIVIL SOCIETY AND PUBLIC LIABILITY IN POST-SOVIET RUSSIA}

\section{Mikhail I. Koshelev}

Dr. Sci. (Philos.), Prof.,

Academy of the Federal Penal Enforcement Service of Russia

1 Sennaya St., Ryazan 390000, Russia

koshelesh@yandex.ru

Viktor E. Vezlomtsev

Cand. Sci. (Philos.), A/Prof.,

Academy of the Federal Penal Enforcement Service of Russia

1 Sennaya St., Ryazan 390000, Russia

ve.vezlomtsev@yandex.ru

Abstract. The article analyzes the concept of "civil society" in interaction with its original concept - "a citizen". This analysis makes it possible to consider the concepts of "citizenship", "civil and state identity", "civil responsibility" in the context of overcoming barriers on the way of civil society development in post-Soviet Russia. The article discusses the interpretations of the concepts of "citizenship" and "civil society".

It is analyzed the tendency not to regard civil society exclusively as an institution of democracy and to reveal it in autocratic regimes. We have considered the civic virtues, thanks to which it is possible to create a mechanism for social interaction, as well as the conditions for the functioning of civil society. It is emphasized the importance of under- 
standing citizenship as "participation", rather than as "allegiance", for the existence of civil society, and the contradictory nature of relations between civil society and the state.

Keywords: state, civil society, state of law, democracy, citizen, public liability, civic identity, state identity, "anti-civil society", corruption

For citation

Koshelev M. I., Vezlomtsev V. E. Civil Society and Public Liability in Post-Soviet Russia. Bulletin of Buryat State University. Philosophy. 2021; 3: 55-66 (In Russ.).

The article was submitted 06.08.2021; approved after reviewing 03.09.2021; accepted for publication 14.09.2021. 